\title{
Footprints of climate change on Mediterranean Sea biota
}

\section{OPEN ACCESS}

Edited by:

Elvira S. Poloczanska, Commonwealth Scientific and Industrial Research Organisation, Australia

Reviewed by: Gil Rilov,

National Institute of Oceanography Israel

Christopher James Brown, Griffith University, Australia

*Correspondence: Núria Marbà

Department of Global Change

Research, Institut Mediterrani

d'Estudis Avançats (Universitat de les Illes Balears-Consejo Superior de Investigaciones Científicas), Miquel Marquès 21, 07190 Esporles, Spain nmarba@imedea.uib-csic.es

Specialty section: This article was submitted to Global Change and the Future Ocean, a section of the journal Frontiers in Marine Science

Received: 08 June 2015 Accepted: 30 July 2015 Published: 13 August 2015

Citation: Marbà N, Jordà G, Agustí S, Girard C and Duarte CM (2015) Footprints of climate change on Mediterranean Sea biota. Front. Mar. Sci. 2:56. doi: 10.3389/fmars.2015.00056

\author{
Núria Marbà ${ }^{1 *}$, Gabriel Jordà ${ }^{2}$, Susana Agusti ${ }^{1,3}{ }^{3}$, Coraline Girard ${ }^{1}$ and \\ Carlos M. Duarte ${ }^{1,3}$
}

' Department of Global Change Research, Institut Mediterrani d'Estudis Avançats (Universitat de les Illes Balears-Consejo Superior de Investigaciones Científicas), Esporles, Spain, ${ }^{2}$ Department of Marine Resources and Ecology, Institut Mediterrani d'Estudis Avançats (Universitat de les Illes Balears-Consejo Superior de Investigaciones Científicas), Esporles, Spain, ${ }^{3}$ Biological and Environmental Sciences and Engineering, Red Sea Research Center, King Abdullah University of Science and Technology, Thuwal, Saudi Arabia

The Mediterranean Sea ranks among the ocean regions warming fastest. There is evidence for impacts of climate change on marine Mediterranean organisms but a quantitative assessment is lacking. We compiled the impacts of warming reported in the literature to provide a quantitative assessment for the Mediterranean Sea. During the last three decades the summer surface temperature has increased $1.15^{\circ} \mathrm{C}$. Strong heat wave events have occurred in years 1994, 2003, and 2009. Impacts of warming are evident on growth, survival, fertility, migration and phenology of pelagic and benthic organisms, from phytoplankton to marine vegetation, invertebrates and vertebrates. Overall, 50\% of biological impacts in the Mediterranean Sea occur at summer surface temperature anomaly $\leq 4.5^{\circ} \mathrm{C}$ and at summer surface temperature of $27.5^{\circ} \mathrm{C}$. The activation energy (geometric mean $1.58 \pm 0.48 \mathrm{eV}$ ), the slope of the Arrhenius equation describing the temperature-dependence of biological processes, for the response of Mediterranean marine biota to warming reveals that these responses in the Mediterranean are far steepest than possibly explained by the direct effect of warming alone. The observations are biased toward the northern and western sectors of the basin, likely underestimating the impacts of warming in areas where warming is particularly intense.

Keywords: temperature, heat wave, species, biological traits, activation energy

\section{Introduction}

The Mediterranean Sea is warming at two to three times the rate for the global ocean (Vargas-Yanez et al., 2008), showing an increase in the occurrence of hot extremes by $200-500 \%$ throughout the region (Diffenbaugh et al., 2007). This is due to a combination of its position in the boundary between two climatic regimes, the arid climate of North Africa and the temperate and rainy climate of central Europe, which renders Mediterranean climate vulnerable to even relatively minor modifications of the general circulation (Giorgi and Lionello, 2008), and its semi-enclosed nature (Diffenbaugh et al., 2007), leading to restricted hydrological exchange with the open ocean, resulting in a hydrological residence time of about 100 years and a capacity to store heat (Bethoux and Gentili, 1999). Indeed, climatic models predict rapid mean warming in the Mediterranean region along with a greater occurrence of extremely high temperature events (Giorgi and Lionello, 2008), also affecting the marine environment (Jordà et al., 2012). Moreover, as a result of its semienclosed nature, marine species endemic to the Mediterranean have a limited scope to adapt to ocean warming by shifting their biogeographical range poleward, tracking the migration of their 
isotherms to maintain their thermal niche (Burrows et al., 2011, 2014), as marine species do in general (Poloczanska et al., 2013).

As a consequence, there is concern on the impacts Mediterranean warming may have on marine biota. A recent review provided a narrative description of the evidence for impacts of climate change on marine biota (Lejeusne et al., 2010), concluding that it is already highly impacted. However, a quantitative assessment of these responses, allowing elucidation of the magnitude of responses, their relationship with warming and the thresholds of warming that are disruptive for various components of the life history and ecology of Mediterranean biota is still lacking. Such assessment would, however, provide a more precise description of the extent of impacts on Mediterranean marine biota already realized with warming and their vulnerability to further warming.

Here we provide a quantitative assessment of the impacts of climate change on Mediterranean biota. We do so by compiling the literature reporting evidence of such impacts, and extracting the conditions of warming relative to long-term mean values, and when these impacts occurred, thereby allowing the derivation of dose-response relationships as well as the identification of possible thresholds of warming beyond which Mediterranean marine biota experience disruptive impacts.

\section{Materials and Methods}

We searched for evidence of footprints of warming on biota in the Mediterranean Sea published in the literature until year 2014 using keywords "(Mediterranean) AND ((Bio* OR Eco*)) AND ((warming OR temperature)) AND ((Marine OR Ocean*)) NOT ((paleo*))" in ISI Web of Knowledge. We also searched for the term "cooling" in the Mediterranean, which retrieved mostly studies of paleo-events, and only one recent study, reporting impacts on zooplankton of a cooling event in 1987 in the Croatian Coast (Berline et al., 2012). From this search we only selected those articles directly attributing the changes observed in marine biota to warming. The type of data collected includes information about characteristics of the study conducted (i.e., year or period of years of the study, site name and coordinates, species name, taxonomic group, whether the species is sessile or mobile, native or introduced) and about the biological response (i.e., type of response, magnitude of response). We grouped the types of biological responses in large trait categories: abundance, survival, fertility, migration, phenology, and growth. The data set includes both qualitative and quantitative data. The data set compiled is publically available at http://digital.csic.es/handle/ 10261/116098 (Marbà et al., 2015).

We compiled a total of 464 evidence impacts of climate change on Mediterranean biota from 54 papers, 11 and 42 of them including narrative and quantitative evidence, respectively, and 1 both. Quantitative reports encompassed evidence of biological impacts after single warming events (276) and during longerterm monitoring assessments (72 time series; Table 1). The time series compiled have a median duration of 24 years (range 3197 years) and a median central year at 1995.5 (range 1908.52004.5). Most impacts compiled are observed at local (43\%) and regional $(50 \%)$ scales while there are few evidence of
TABLE 1 | Number of descriptive and quantitative reports compiled of footprints of climate change on Mediterranean biota at local, regional, sub-basin, and Mediterranean scales.

\begin{tabular}{lccccc}
\hline $\begin{array}{l}\text { Type of } \\
\text { evidence }\end{array}$ & Local & Regional & $\begin{array}{l}\text { Sub-basin } \\
\text { (Western, } \\
\text { Central, } \\
\text { Eastern) }\end{array}$ & Mediterranean & Total \\
\hline $\begin{array}{l}\text { Descriptive } \\
\text { Quantitative }\end{array}$ & 16 & 109 & 0 & 1 & 126 \\
$\begin{array}{l}\text { Event-based } \\
\text { Time-series }\end{array}$ & 156 & 110 & 7 & 3 & 276 \\
Shifts & 27 & 10 & 1 & 18 & 56 \\
\hline
\end{tabular}

The number of reports of impacts assessed from heat waves (event-based) and timeseries and the number of reported thermal shifts in natural populations are indicated.

footprints of warming at sub-basin (2\%) and basin (5\%) scales (Table 1).

The information provided by the articles about the temperature associated to each reported impact was very heterogeneous. Different papers used different temperature diagnostics (e.g., monthly mean, instantaneous values), from different instruments and at different depths. Therefore, in order to use a homogenized temperature diagnostic, we have used the sea surface temperature (SST) at each specific location where an impact has been reported. In particular, we have computed the 99th percentile of the year of the impact $\left(\mathrm{SST}_{\mathrm{p} 99}\right)$ at the location where the impact has been reported [thus $\mathrm{SST}_{\mathrm{p} 99}$ is a function of space $(x)$ and time $(t)$ ]. Then, we express it as anomaly with respect to the averaged august temperature computed for the period 1960-1985 for the same location $\left[\Delta \operatorname{SST}_{\mathrm{p} 99}(x, t)=\mathrm{SST}_{\mathrm{p} 99}\right.$ $\left.(x, t)-\mathrm{SST}_{\text {Aug } 1960-1985}(x)\right]$. August was chosen as the reference period because this is the month when the highest sea surface temperatures are reached in the Mediterranean. Hence, this is the time when warming impacts are most likely to be observed, as extreme temperature, when organisms may be exposed to temperature beyond their optima, are concentrated in August. Other diagnostics as the yearly maximum or the averaged summer temperature lead to similar conclusions.

The SST database used in this study spans the period 1960-2011 at daily frequency with a spatial resolution of $1 / 8^{\circ}$ $(\sim 10 \mathrm{~km})$. For the period $1980-2011$ we have used SST satellite observations. In particular, we have used the MyOcean reanalysis product which consists in a reprocessing of Pathfinder V5.2 (PFV52) AVHRR data (Casey et al., 2010) and provides daily gap-free maps (L4) of the foundation SST at the original PFV52 resolution at $1 / 24^{\circ}$ (Nardelli et al., 2013). In order to reduce observational noise, the resolution of the satellite data has been degraded to $1 / 8^{\circ}$ through cell averaging. For the period 19601980 , we have used the outputs of an atmosphere-ocean regional climate model, the PROTHEUS system (Artale et al., 2010). The model is driven by ERA40 reanalysis fields at the lateral boundaries and provides daily means of SST for the period 19602000 with a spatial resolution of $1 / 8^{\circ}$. The period $1980-2000$ has been used to calibrate the model outputs with satellite data in order to remove the model bias and to adjust the amplitude of the 
seasonal cycle. Then, the calibrated model outputs for the period 1960-1980 have been included in the database.

We used the temperature records (annual SST, SST for a particular season and occasionally in situ temperature) provided by the papers when changes in marine biota were assessed from long-term observations, except in two cases (Nincevic-Gladan et al., 2010; Mazzocchi et al., 2012) that we obtained SST time series for the study period as described above.

We quantified the effect of warming on biological parameters through the Activation Energy (E, in eV, Brown et al., 2004), which provides a metric of the relative temperature-dependence or sensitivity of a particular property or process. The activation energy has been shown to provide an adequate, predictable and robust description of the temperature-dependence of biological processes across a scales or organization ranging from molecular and evolutionary processes, to physiological, organismal and community and ecosystem levels (Brown et al., 2004; Dell et al., 2011). Whenever a time series describing interannual changes in biological properties was available, the Activation Energy ( $E$, in $\mathrm{eV}$ ) was derived as the slope of the Arrhenius equation,

$$
\ln (V)=C+\left[E *\left(\frac{1}{k T}\right)\right]
$$

where $V$ is the value of the biological parameter or rate process, $C$ is the intercept of the fitted regression equation, $k$ is the Boltzmann constant and $T$ is the temperature (in $\mathrm{K}$ ).

Where impacts were reported as departures of values observed during a thermal anomaly $\left(V_{i}\right)$ relative to a previous observation $\left(V_{\mathrm{o}}\right)$ observed for temperature $T_{i}$ and $T_{0}$ (in $\mathrm{K}$ ), respectively (where $T_{o}<T_{i}$ ), an effect size per unit temperature, equivalent to $E$, was calculated, assuming the differences to conform to an Arrhenius model, as:

$$
E=\frac{\ln \frac{V_{0}}{V_{i}}}{\frac{1}{k T_{i}}-\frac{1}{k T_{0}}}
$$

$E$ calculated in this manner is equivalent to a ln effect size (Hedges et al., 1999) typically used to compare the magnitude of responses across multiple response variables in meta-analysis (e.g., Kroeker et al., 2013). When the trait decreased with temperature (e.g., net growth rates), the ratio was rearranged (i.e., $\ln \frac{V_{i}}{V_{0}}$ ) to provide all $E$ estimates as positive values thereby facilitating comparison of effect size across biological traits.

\section{Results}

\section{Warming Rates in the Mediterranean: Observations and Model Hindcast}

The average summer SST ranges from 22 to $28^{\circ} \mathrm{C}$ with the highest values in the Levantine basin and the lowest in the north Aegean, the north western Mediterranean and the Alborán sea (Figure 1A). These local minima are caused by different factors. In particular, the minimum in the Alborán Sea is linked to the inflow of colder Atlantic waters through the Strait of Gibraltar. The minimum in the NW Mediterranean can be attributed to the

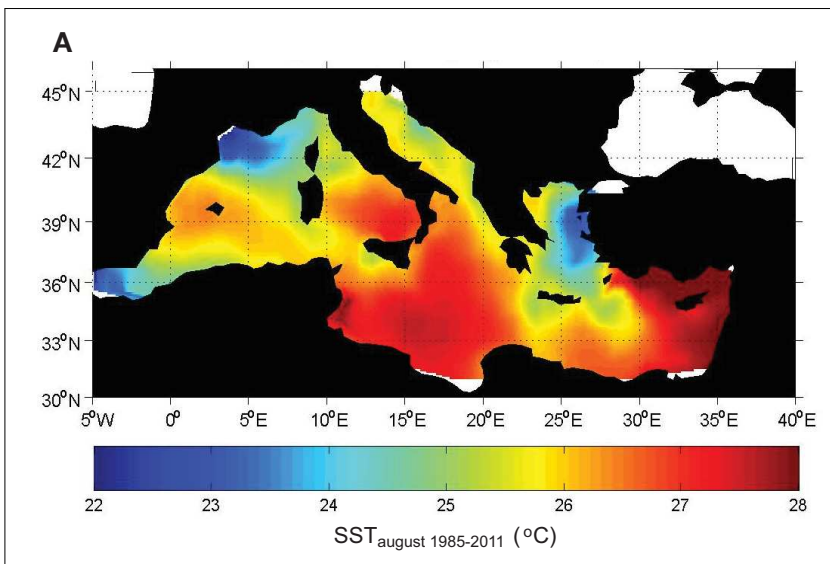

B

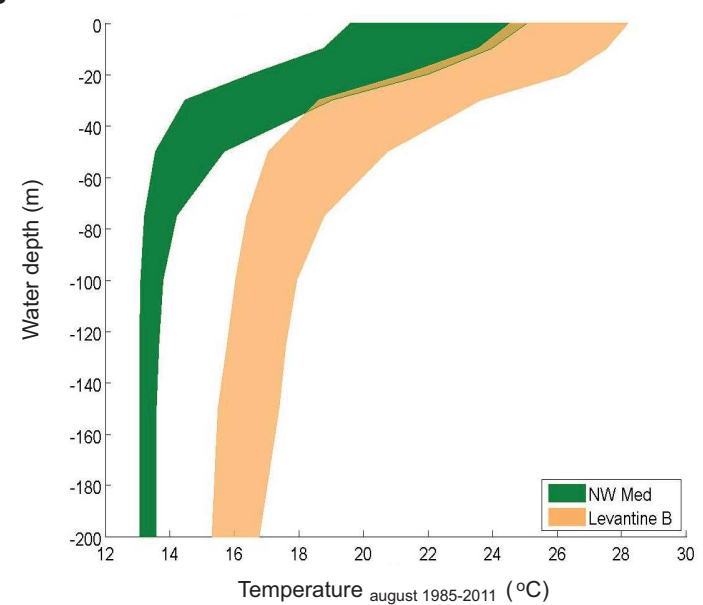

FIGURE 1 | Averaged Sea Surface Temperature for August during the period 1985-2011 (A) and averaged vertical profiles of temperature for August during the period 1985-2011 in the North Western Mediterranean $\left(0-13^{\circ} \mathrm{E}, 40-45^{\circ} \mathrm{N}\right)$ and the Levantine basin $\left(30-40^{\circ} \mathrm{E}\right.$, $\left.31-37^{\circ} \mathrm{N}\right)(B)$.

strong winds acting in that area enhancing vertical mixing and therefore cooling the surface waters. Finally, the minimum in the north Aegean can be explained by a combination of the inflow of cold waters from the Black Sea through the Dardanelles strait and the action of local winds. Concerning the vertical structure of the summer temperature field, it is characterized by a strong stratification in the upper layer. Temperature decreases almost linearly by about $7-8^{\circ} \mathrm{C}$ over the top $50 \mathrm{~m}$ water layer $(0.14-$ $0.16^{\circ} \mathrm{C} \mathrm{m}^{-1}$ ) in both the eastern and western basins (Figure 1B), and it remains relatively uniform at deeper water.

Linear trends were fitted to the satellite SST for the period 1985-2011 in order to characterize multidecadal changes in summer SST (Figure 2). During the last three decades the summer surface temperature has increased, on average, $1.15^{\circ} \mathrm{C}$. During this period, the warming trends range from $0.25^{\circ} \mathrm{C}$ decade $^{-1}$ in the western basin to $0.65^{\circ} \mathrm{C}$ decade $^{-1}$ in the eastern basin. The increase of the summer mean temperature, an important factor affecting biota is the occurrence of heat waves. We characterize heat waves as periods where SST at a particular location exceeded the 99th percentile of a reference 


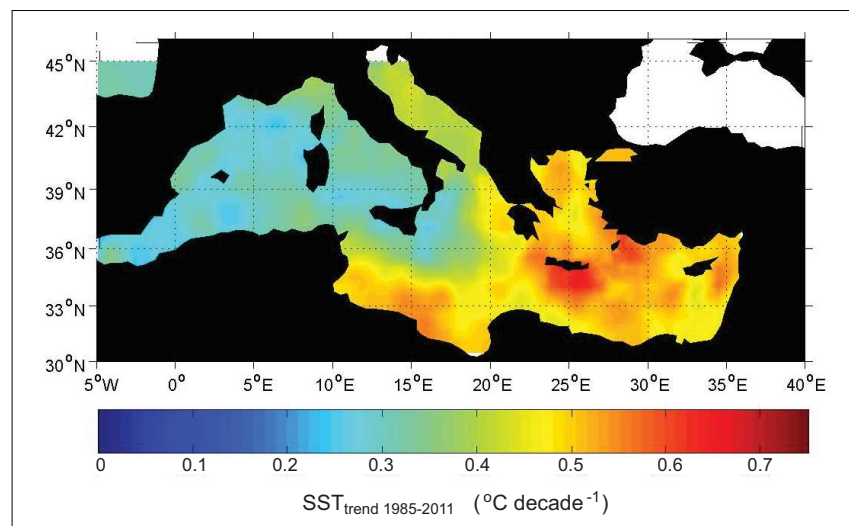

FIGURE 2 | Sea Surface Temperature Trend (in ${ }^{\circ} \mathbf{C}$ decade ${ }^{-1}$ ) computed for the period 1985-2011 using satellite data.

period (here 1960-1985) at the same location. The intensity of the heat wave at a given location is expressed in ${ }^{\circ} \mathrm{C}$ degreedays and is computed by integrating the excess temperature above the given threshold (in ${ }^{\circ} \mathrm{C}$ ) during the time the threshold has been exceeded (in days). The annual 99th percentile shows a significant interannual variability with basin averaged values ranging from $25.1^{\circ} \mathrm{C}$ in 1984 to $29.3^{\circ} \mathrm{C}$ in 2003 (Figure 3A). Also, a multidecadal variability is also apparent with a minimum in the 70's and a significant increase since the mid 80's until present, in good agreement with the multidecadal change of the mean SST already reported by Mariotti and Dell'Aquila (2012). Concerning the heat wave intensity, there is also a strong interannual variability (standard deviation of $20^{\circ} \mathrm{C}$ degree-days) with strong heat wave events reaching up to 100,60 , and $50^{\circ} \mathrm{C}$ degree-days in 2003, 2009, and 1994, respectively (Figure 3B). The decadal variability in the heat wave intensity also follows the changes observed in the 99th percentile. During the 60's the averaged intensity was $15^{\circ} \mathrm{C}$ degree-days, during the 70 's and until mid 80 's the intensity was almost zero and since then the intensity has been rising. During the period 2000-2010 the averaged heat wave intensity was $40^{\circ} \mathrm{C} \cdot$ degree-days.

Heat waves are not basin-wide processes and large differences can be found regionally. For instance, during 1998 a heat wave affected the Adriatic, the Ionian and parts of the Levantine basin (Figure 4A). In those regions the heat wave intensity was 60$75^{\circ} \mathrm{C}$ degree-days while in the rest of the basin it was hardly larger than $10^{\circ} \mathrm{C}$ degree-days. The 2003 heat wave affected a much larger area (Figure 4B). Almost the whole western Mediterranean, the Adriatic and central Mediterranean were affected by a long and intense heat wave that reached over $120^{\circ} \mathrm{C}$ degree-days in most of those areas. Conversely, the Alborán Sea, the Levantine basin and the Aegean Sea did not experience any heat wave that year.

\section{Footprints of warming on Mediterranean Biota}

A large number of impacts of warming on Mediterranean biota have been reported since year 1950, but $90 \%$ of them have been observed after 1987 (Figure 5). Most (61\%) event-based biological impacts occurred in years 1994-1995, 1999, and 2003
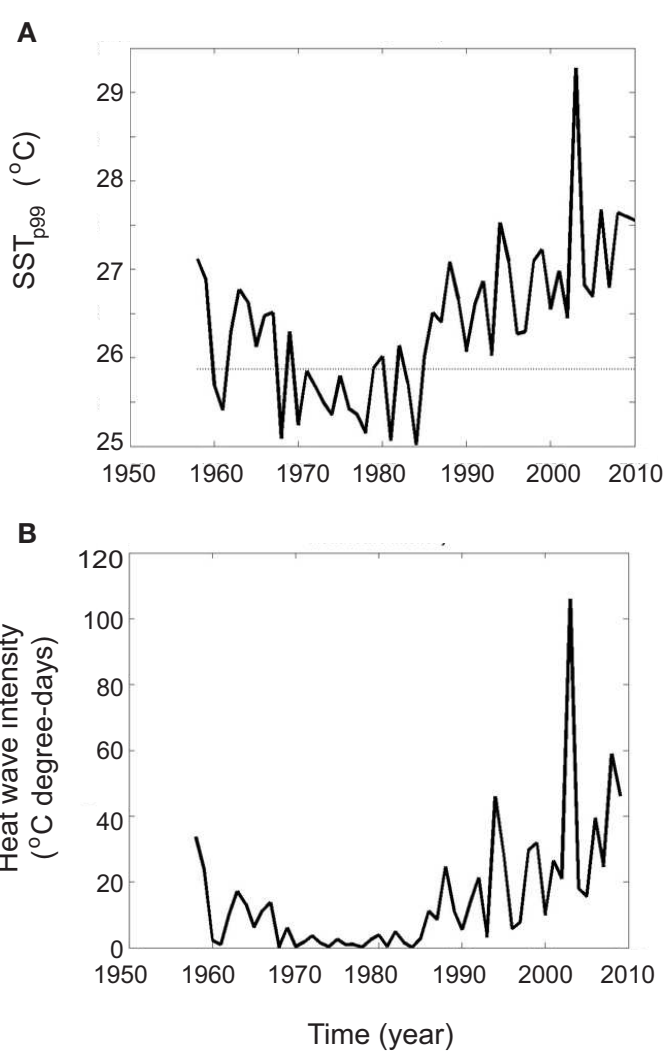

FIGURE 3 | Time series of basin average SST of 99th annual percentile (SST p99 in ${ }^{\circ} \mathrm{C}, \mathrm{A}$ ) and of basin average of heat wave intensity (in ${ }^{\circ} \mathrm{C}$ degree-days, B). The dotted line in plot $A$ indicates the basin average of the reference value used to characterize the heat waves.

(Figure 5). Despite most (90\%) long term changes in marine biota attributed to warming follow linear trends, there are some evidence (6 out of 72) of abrupt shifts in Mediterranean biota attributed to shifts in SST in 1970, the end of the 80's and the end of the 90's (Supplementary Table 1).

Evidence of warming impacts on Mediterranean biota are largely (94\%) concentrated in the North Western Mediterranean basin and the Adriatic Sea (Figure 6). No impacts are reported along the Southern Mediterranean coast, except Tunisia, and few impacts have been described in the central and eastern Mediterranean sub-basins (Figure 6). Mediterranean warming is already affecting the fitness of marine biota, as reflected by reports of changes in abundance, survival and fertility, their phenology and triggering species migration (Figure 6). Population abundance and survival are the biological traits accounting for most (68\%) reported impacts of Mediterranean warming. Yet, migration of native and introduced (mostly Lessepian) species accounts for $15 \%$ of total biological footprints of Mediterranean warming (Figure 6). Footprints of Mediterranean warming have been observed in several marine phylum, including populations of invertebrates (porifera, cnidaria, polychaeta, mollusca, ascidians, bryozoa, echinodermata, crustaceans), vertebrates (fishes, reptiles, mammals), phytoplankton, and macrophytes (macroalgae and seagrasses). However, most (53\%) evidence of 


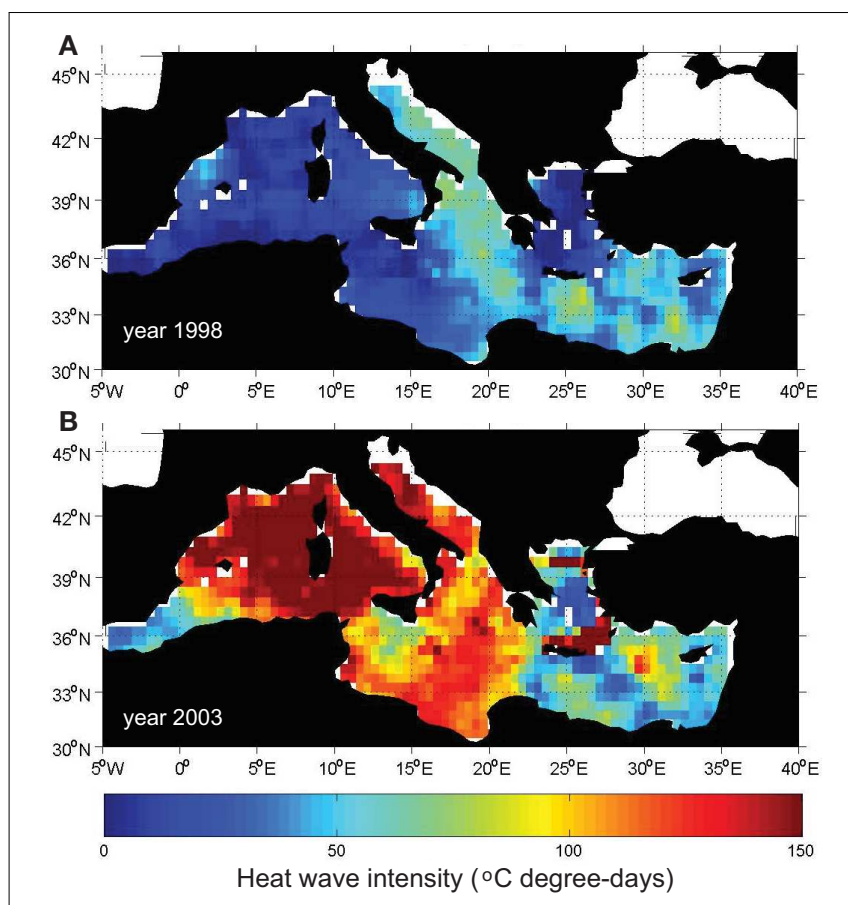

FIGURE 4 | Heat wave intensity for years 1998 (A) and 2003 (B) across the Mediterranean Sea.

impacts of warming on Mediterranean biota are reported for fish and cnidaria.

Impacts of warming on marine species living in the Mediterranean Sea have been observed at $\mathrm{SST}_{\mathrm{p} 99}$ anomalies up to $5.5^{\circ} \mathrm{C}$ (Figure 7). However, the frequency of anomalies decreases with anomaly strength. Thus, we corrected the thermal anomaly distribution of impacts for the frequency of occurrence of anomalies by dividing the number of impacts observed by the number of $\mathrm{SST}_{\mathrm{p} 99}$ anomalies within $0.5^{\circ} \mathrm{C}$ increments occurred since 1960. The magnitude of warming triggering impacts on Mediterranean marine biota varied across biological traits (Figure 7). Fertility is the biological trait that risks to be largely impacted by mild warming ( $50 \%$ probability of impact at $\mathrm{SST}_{\mathrm{p} 99}$ anomaly $\leq 1^{\circ} \mathrm{C}$ ), followed by migration (50\% probability of impact at $\mathrm{SST}_{\mathrm{p} 99}$ anomaly $\left.\leq 2{ }^{\circ} \mathrm{C}\right)$ and abundance $(50 \%$ probability of impact at $\mathrm{SST}_{\mathrm{p} 99}$ anomaly $\leq 2.5^{\circ} \mathrm{C}$, Figure 7 ). Conversely, $50 \%$ of impacts on phenology and survival occur at large $\mathrm{SST}_{\mathrm{p} 99}$ anomalies up to 3 and $4.5^{\circ} \mathrm{C}$, respectively (Figure 7). Similarly, $\mathrm{SST}_{\mathrm{p} 99}$ exceeding $27.5,25.5,26,28$, and $28.5^{\circ} \mathrm{C}$, respectively, triggers the probability of impact above of $50 \%$ on fertility, migration, abundance, phenology and survival of species living in the Mediterranean Sea, respectively (Figure 8). Overall, $50 \%$ of biological impacts in the Mediterranean Sea occur at $\mathrm{SST}_{\mathrm{p} 99}$ anomaly $\leq 4.5^{\circ} \mathrm{C}$ (Figure $9 \mathrm{~A}$ ) and at $\mathrm{SST}_{\mathrm{p} 99}$ of $27.5^{\circ} \mathrm{C}$ (Figure 9B).

The sensitivity of Mediterranean biota to warming varies across taxonomic groups. 50\% of the impacts on ascidiacea, crustacea, echinodermata, fish, and phytoplankton occur at $\mathrm{SST}_{\mathrm{p} 99}$ anomaly up to 2 or $2.5^{\circ} \mathrm{C}$, whereas those on cnidaria, mollusca and porifera, and seagrasses occur at $\mathrm{SST}_{\mathrm{p} 99}$ anomaly up

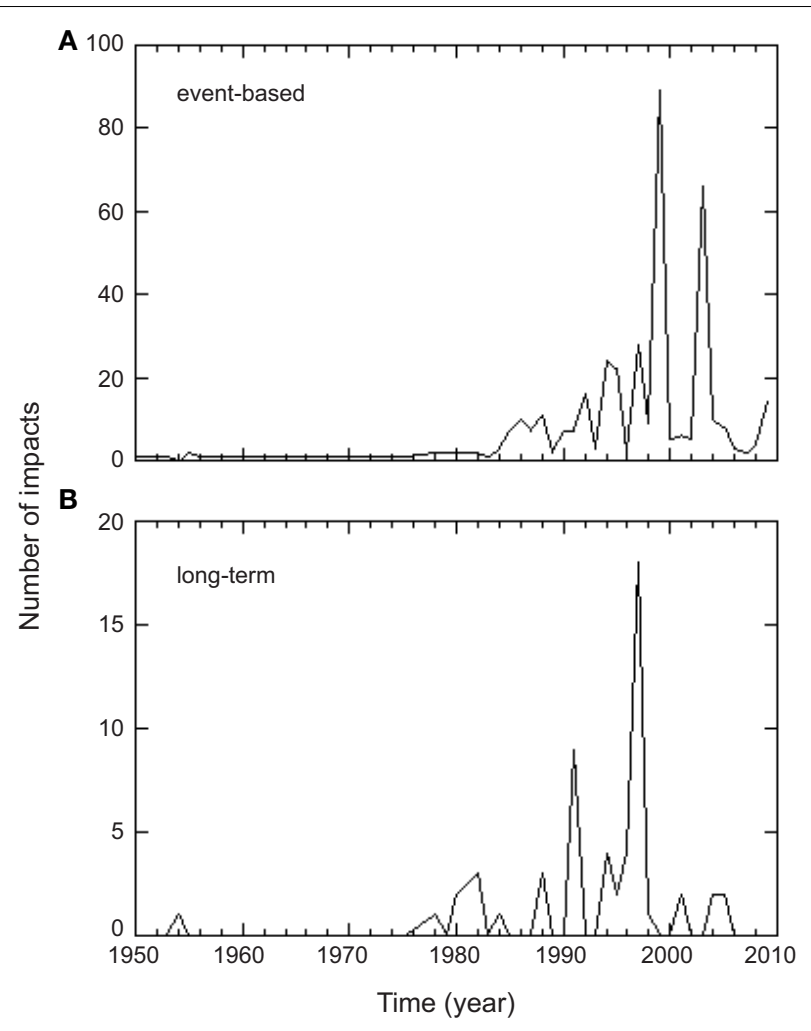

FIGURE 5 | Time series of the number of biological impacts attributed to Mediterranean warming assessed $(A)$ from single warming events and (B) from long-term observations. The number of impacts assessed from long-term observations corresponds to the number of time-series exhibiting significant linear trends between biological parameters and temperature. Time in (B) corresponds to the central year of the observational period of each study (median duration 24 years).

to $5^{\circ} \mathrm{C}$ (Figure 10). The observed thermal anomalies impacting sessile marine organisms $(76.6 \%$ affected survival and $1 \%$ phenology) on average are three-fold higher $\left(1.51 \pm 0.11^{\circ} \mathrm{C}\right.$, $N=197)$ than those $\left(0.59 \pm 0.09^{\circ} \mathrm{C}\right)$ impacting motile biota $(4 \%$ affected survival and $4.1 \%$ phenology).

Because the attribution of reported impacts to warming at $\mathrm{SST}_{\mathrm{p} 99}$ anomalies smaller than $2^{\circ} \mathrm{C}$ (Figure 9A) involves considerable uncertainty, we defined a threshold at $2{ }^{\circ} \mathrm{C}$ thermal difference, above which the attribution of estimated effect sizes to Mediterranean warming is likely robust, to assess the magnitude of the responses. Most (63\%) of quantified changes in marine biological activity in the Mediterranean Sea, however, have been documented for thermal differences below $2{ }^{\circ} \mathrm{C}$. Calculation of the activation energy of biological activity could reach extremely large, abnormal values for thermal anomalies below $2^{\circ} \mathrm{C}$ (Supplementary Figure 1), thereby inflating the possible response of organisms to warming. When Mediterranean warming involves thermal differences exceeding $2^{\circ} \mathrm{C}$, the median activation energy of marine biological activity is $2.25 \mathrm{eV}$ (Figure 11), although when assessed from event-based observations $(1.69 \mathrm{eV})$ is about half that estimated from time series $(3.65 \mathrm{eV})$. However, the geometric mean of activation 


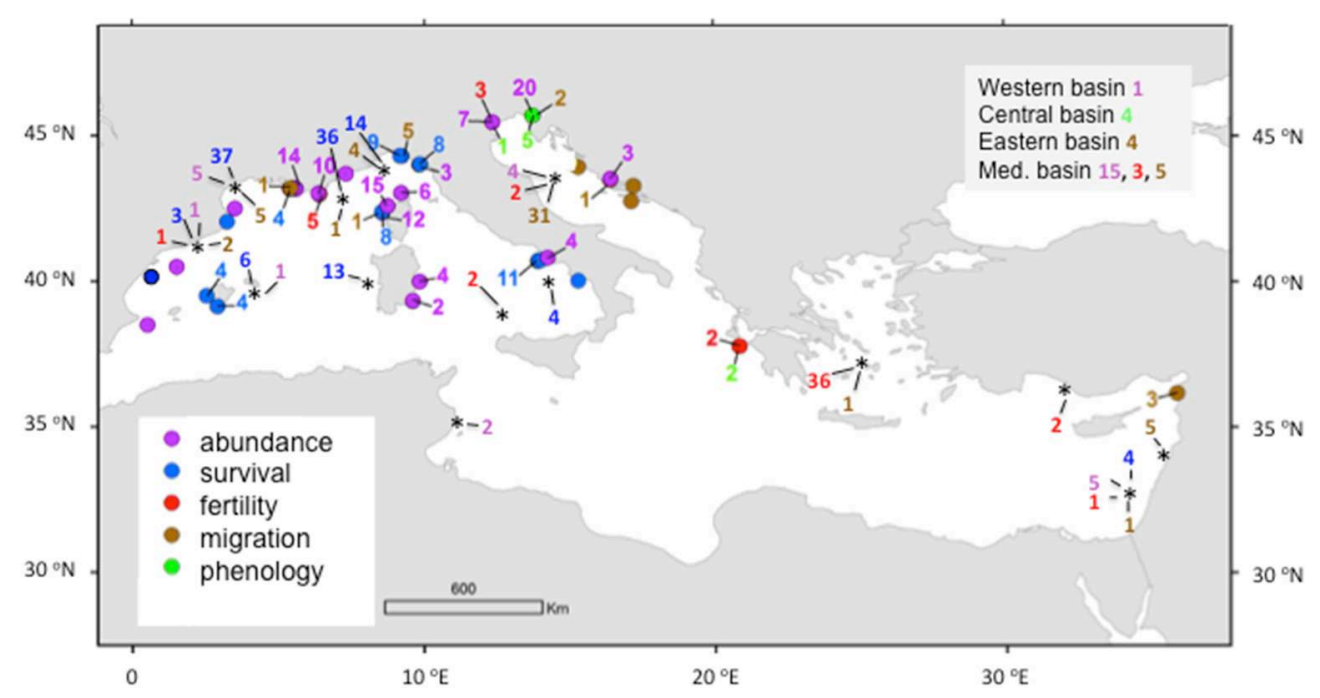

FIGURE 6 | Location of the reported impacts of temperature on biota in the Mediterranean Sea. The color of dots and numbers indicates the category of impact reported. The numbers next to the dots and quadrats show the number of impacts per impact category reported per site when it exceeds one. Impacts reported at local (color dots), regional (asterisks), sub-basin (Western, Central, Eastern Mediterranean), and Mediterranean basin scales are indicated. energy of Mediterranean marine biological traits is comparable for event-based observations $(1.24 \pm 0.58 \mathrm{eV})$, and time-series observations $(2.69 \pm 0.78 \mathrm{eV})$, with an overall geometric mean activation energy of $1.58 \pm 0.48 \mathrm{eV}$ (Figure 11). Abundance and reproduction rates tend to be the traits displaying a steepest response to warming, followed my survival and phenology shifts, and migrations show, comparatively, a limited response (Figure 11).

\section{Discussion}

The warming trend of $0.25^{\circ} \mathrm{C}$ decade $^{-1}$ in the western basin and $0.65^{\circ} \mathrm{C}$ decade $^{-1}$ in the eastern basin can be partially explained by an increase of the Atlantic Multidecadal Oscillation (AMO) index. Mariotti and Dell'Aquila (2012) have shown that multidecadal variability of Mediterranean SST is highly correlated with AMO. AMO has been increasing during the last 40 years, which could explain an increase of about $0.10-0.15^{\circ} \mathrm{C}$ decade $^{-1}$ in the Mediterranean SST during that period. The rest of the trend may be linked to global warming. Unfortunately up to our knowledge there are no dedicated studies on the attribution of recent Mediterranean warming to confirm this apportioning of warming trends.

The synthesis presented documents a large number $(>450)$ of reported impacts of warming on the Mediterranean Sea, one of the rapid warming areas in the ocean (Hoegh-Guldberg et al., 2014). The geographical distribution of these reports reflects, to a large extent, the distribution of marine research institutions, with a high density of observations in the NW Mediterranean and a remarkable paucity of observations along the Northern African coast. This is unfortunate, as the NW Mediterranean is the area in the Mediterranean Sea with the most moderate long-term warming trend, whereas rates of warming were much higher in the Eastern basin and along the African coast from Algeria to Israel (Figure 2). Also, impacts driven by invasive behavior propelled by warming of lessepian migrants reaching the Mediterranean from the Red Sea are likely to be greatest in the Eastern basin. On the other hand, the intense research effort in the NW Mediterranean allowed for a thorough documentation of the impacts of the 2003 heat wave, the strongest recorded in the Mediterranean over at least the past 50 years and that is responsible for a high fraction $(17 \%)$ of the reports of warming impacts on Mediterranean biota. Indeed, most reports were event-based rather than derived from time-series analyses, which weakens the attribution of these impacts to warming and, particularly, its anthropogenic component, which requires multi-decadal time series (Parmesan et al., 2013; O'Connor et al., 2014). An assessment of the robustness of studies assessing the impacts of climate change on Mediterranean biota shows these to be, on average, weaker than those available in the general field of climate change ecology (O'Connor et al., 2014). In particular, the studies for the Mediterranean suffer from insufficient data, particularly due to the prevalence of event-based observations, and inappropriate statistical analyses. In contrast, the expectations were formulated in a more explicit manner than usually encountered in the field.

There has been much discussion as to the role of anthropogenic climate change (very likely, confidence level $>90 \%$, that human influence was responsible, e.g., Stott et al., 2004) vs. other processes (e.g., aerosols from Saharan dust and forest fires, Lyamani et al., 2006) in causing the 2003 heat wave, upon which a significant fraction of the evidence rests. Regardless of whether the impacts associated with the 2003 heat in the NW Mediterranean can be attributed to anthropogenic climate change or not, this heat wave provides a proxy of 


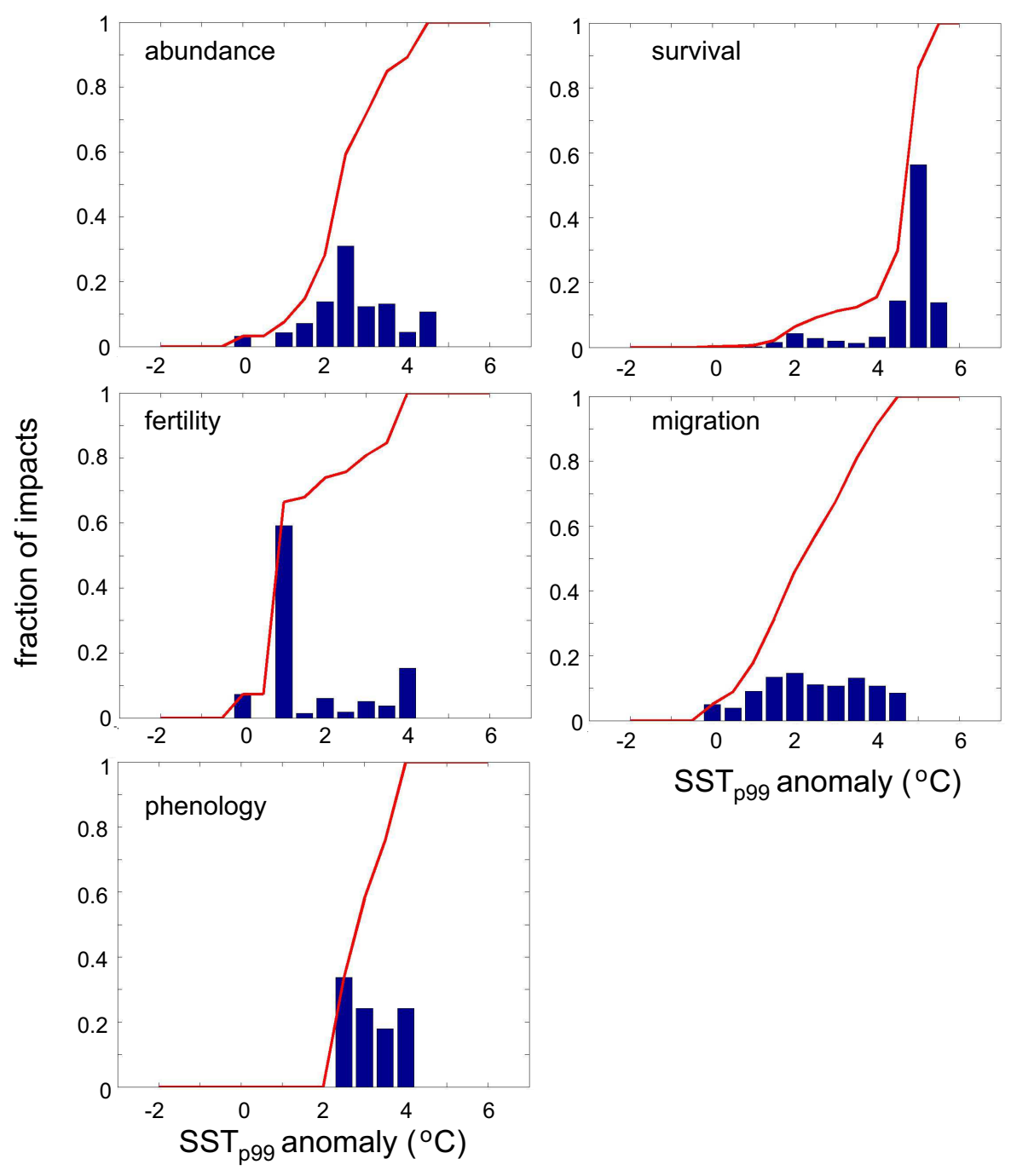

FIGURE 7 | Corrected histogram of the number of reported impacts as a function of SST 99 anomaly (see text for details) for each trait: abundance, survival, fertility, migration, and phenology. The red line in each plot indicates the cumulative probability.

the impacts to be expected in the future when downscaled models predict that heat waves of this magnitude will become frequent (Jordà et al., 2012). The 2003 heat wave event was reported to result in mortality of benthic organisms, including gorgonians, sponges, molluscs, bryozoos (e.g., Garrabou et al., 2009; Bensoussan et al., 2010) and seagrass (Posidonia oceanica, Díaz-Almela et al., 2009; Marbà and Duarte, 2010) as well as mass flowering of $P$. oceanica (Díaz-Almela et al., 2007). These observations provide indications of the impacts that may be expected with future climate change in the Mediterranean, where the projected increased in the frequency and magnitude of heat waves will compromise the most vulnerable ecosystems, such as coral and P. oceanica meadows (e.g., Jordà et al., 2012).

The distribution of reports by taxa is dominated by reports on fish and cnidaria. This distribution of reports reflects a mixture of the vulnerability of the taxa and the availability of data. For instance, the existence of systematic and regular fishery surveys has provided a robust basis for the evaluation of the response of fishes to warming, not only in terms of the data available but the fact that these are usually available as time-series, which provide a stronger basis for detection and attribution (Parmesan et al., 2013; O'Connor et al., 2014). The availability of high qualitydata for fish communities is likely responsible for the fact that impacts on fish were detected and reported at lower temperature anomalies (median $2.0^{\circ} \mathrm{C}$ ) than reported for other taxa (overall median $5.0^{\circ} \mathrm{C}$, Figure 10). In contrast, cnidaria, for which also a substantial (for not as high-quality) observational basis was available, seem to be more resistant to warming, as impacts were observed at relatively higher temperature anomalies (median $5.0^{\circ} \mathrm{C}$, Figure 10).

Examination of the reports of impacts in relation to the weighted (by frequency of occurrence) thermal anomalies 


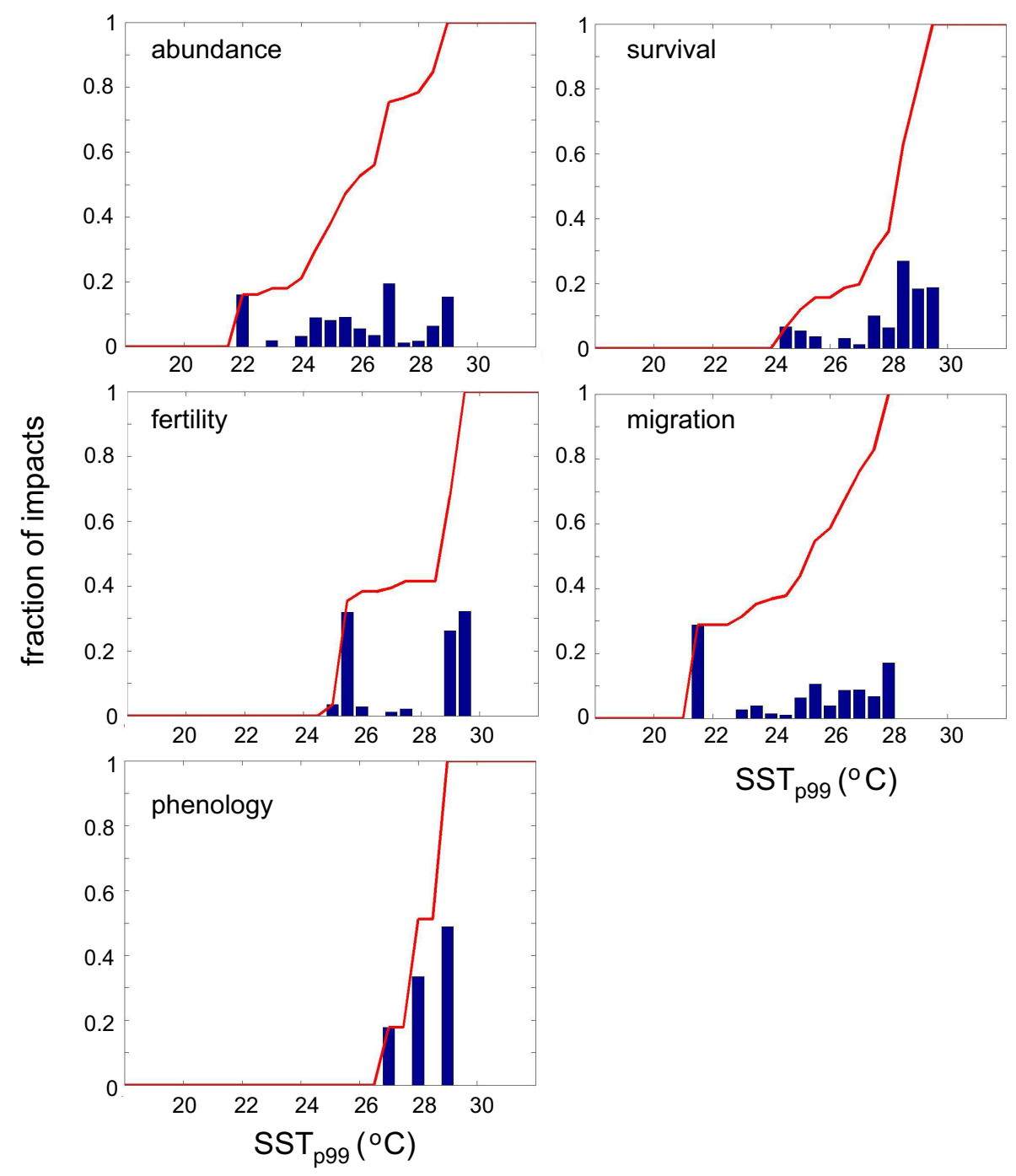

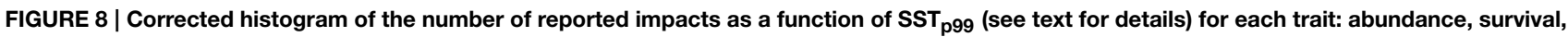
fertility, migration, and phenology. The red line in each plot indicates the cumulative probability.

showed that some impacts seem to respond continuously to warming, such as those on abundance, migration and phenology (Figure 7). It also showed that a number (2\%) of reports of impacts which attribution to warming seem questionable, as impacts were reported with no, or negative, thermal anomalies (i.e., in the absence of evidence of warming or even in cooling periods, Figure 9A). In contrast, reports of enhanced mortality with warming showed a threshold behavior, where the likelihood of finding enhanced mortality increased abruptly at temperature anomalies in excess of $4^{\circ} \mathrm{C}$.

The examination of activation energy for the response of Mediterranean marine biota to warming reveals a prevalence of high $(>1 \mathrm{eV})$ activation energy values (geometric mean $1.58 \pm 0.48 \mathrm{eV}$ ), which is about three-fold higher than the activation energy the metabolic theory of ecology assumes to govern biological processes (Brown et al., 2004). This implies that biological responses to warming in the Mediterranean are far steepest than possibly explained by the direct effect of warming alone. Indeed, warming affects a number of processes, in addition to its direct effect on biological processes. For instance, warming affects the strength of vertical stratification in the Mediterranean, which in turn affects turbulent nutrient supply to the photic layer, reducing primary production in the stratified season (e.g., Doney, 2006). Indeed, warming is leading to reduced primary production in the subtropical and tropical ocean (Boyce et al., 2010) and an expansion of the subtropical gyres (Polovina et al., 2008), largely through this mechanism. Moreover, warming does not occur in isolation but concurrently with other stresses, such as pollutant inputs (Duarte, 2014), where warming can amplify the sensitivity of organisms to other stresses. For instance, research in a Mediterranean Bay has shown that the probability of hypoxia increases with temperature 


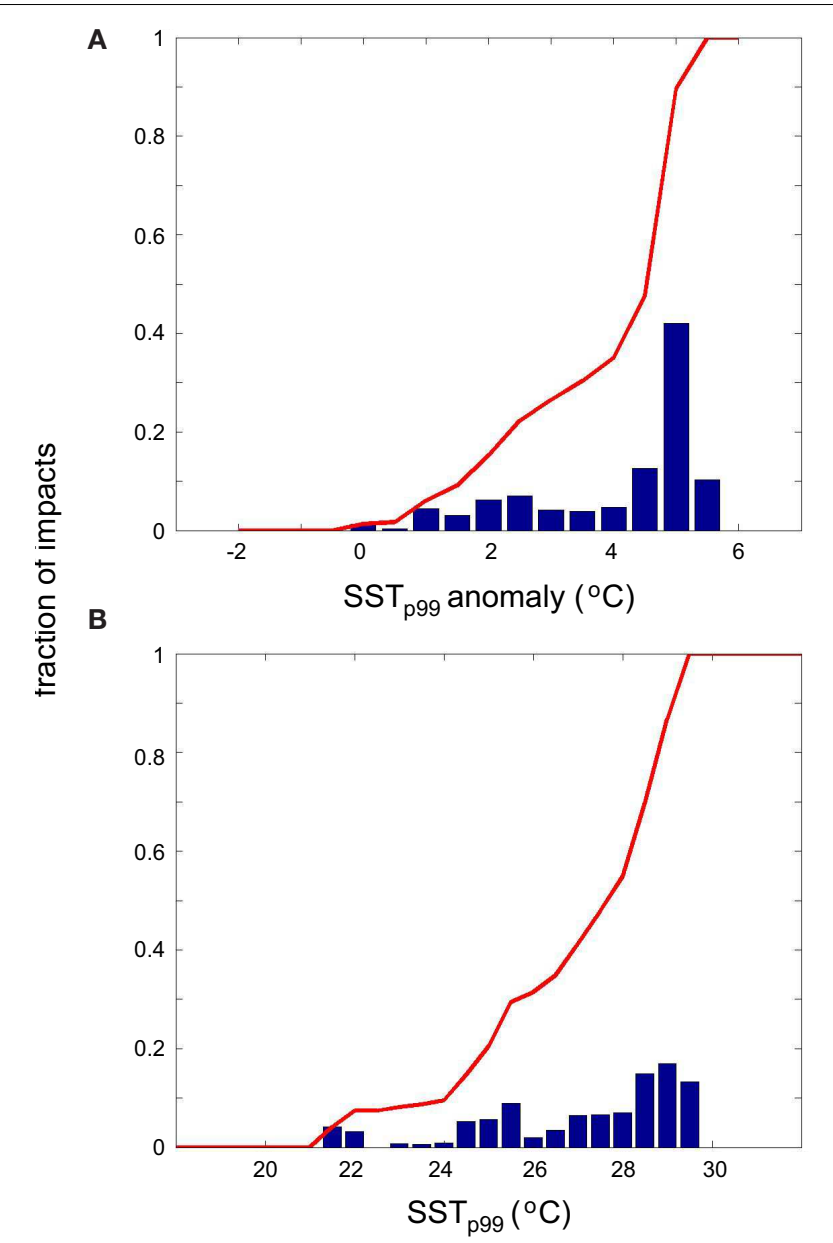

FIGURE 9 | Corrected histograms of the number of reported impacts as a function of $\mathrm{SST}_{\mathrm{p99}}$ anomaly (A) and as a function of $\mathrm{SST}_{\mathrm{p} 99}(\mathrm{~B})$ for all traits.

(Vaquer-Sunyer et al., 2012), while warming also increases metabolic oxygen consumption (Regaudie-de-Gioux and Duarte, 2013) and raises the thresholds of oxygen concentration for hypoxia-induced stresses in marine organisms (Vaquer-Sunyer and Duarte, 2011). Hence, the geometric mean empirical activation energy of $1.58 \pm 0.48 \mathrm{eV}$ reported here for marine Mediterranean biota compounds the direct and indirect effects of warming and identifies a steeper response to warming than expected based on metabolic theory alone. The limited activation energy for migration compared to other traits likely reflects the confined nature of the Mediterranean basin, where organisms have limited scope for poleward migration (Burrows et al., 2011, 2014), thereby limited the role of migration as an adaptive strategy to cope with climate change (Poloczanska et al., 2013).

In summary, the synthesis presented here provides widespread evidence of severe impacts of warming on Mediterranean biota, mostly associated with the recent heat waves affecting this region, in particular the 2003 heat wave affecting the NW Mediterranean. The observations, however,

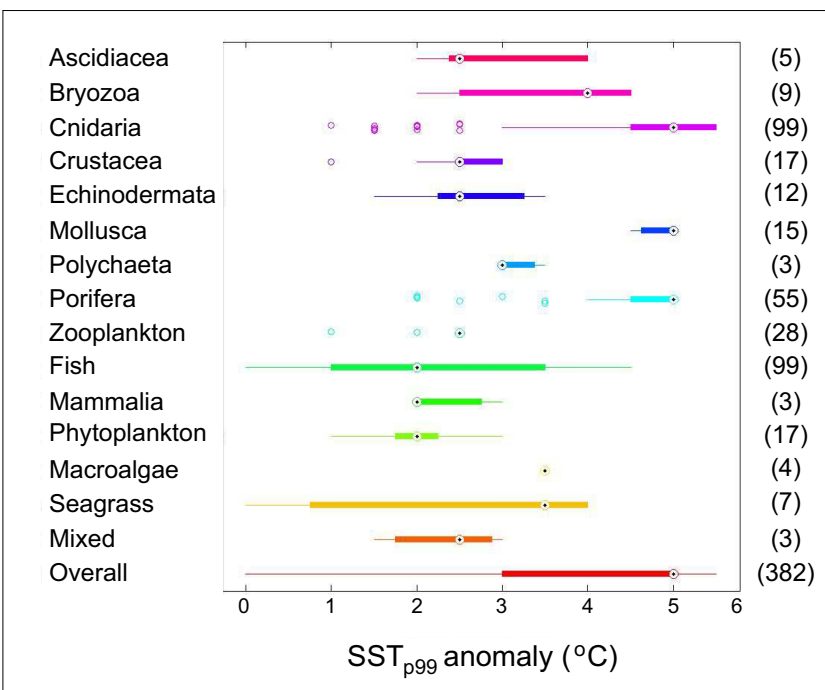

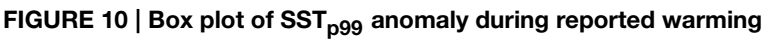
impacts across taxonomic groups of Mediterranean biota. The number of single estimates is shown within brackets. Impact observations are corrected by the temperature anomaly distribution at the sites for the period 1950-2011.

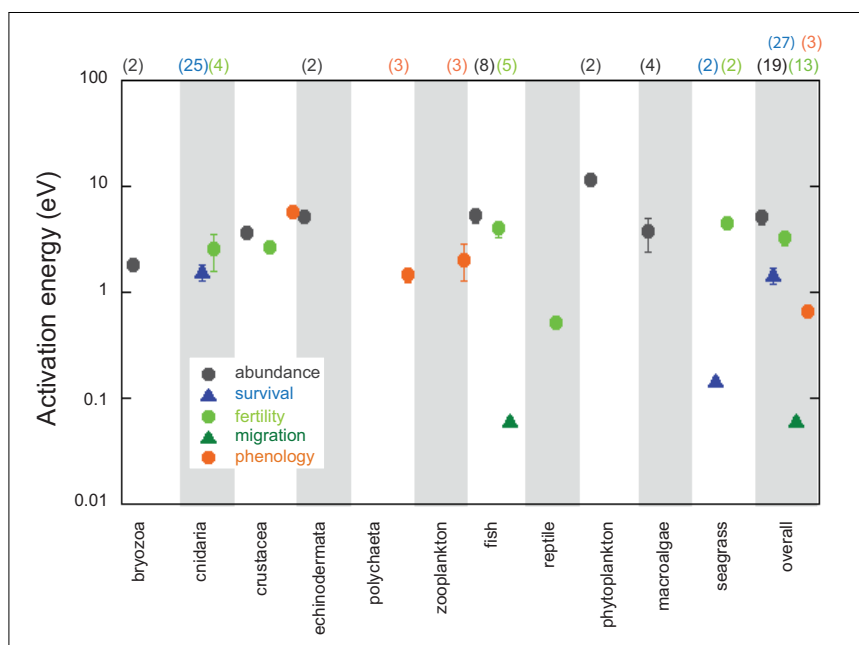

FIGURE 11 | Mean activation energy of biological traits (abundance, survival, fertility, migration, phenology) across taxonomic groups and overall calculated from event-based and long-term observations. Error bars are standard error of the mean value. The number of observations per taxon and trait category, when greater than one, is indicated within brackets. Only activation energy estimates for a temperature range exceeding $2^{\circ} \mathrm{C}$ are included.

are biased toward the northern and western sectors of the basin, where research institutions and, therefore, effort aggregate, likely underestimating the impacts of warming in areas, such as the African coast and Eastern basin where warming is particularly intense. The reported impacts of warming should be considered with caution when these are associated with thermal anomalies less than $2^{\circ} \mathrm{C}$, as the reported warming derives largely, but not exclusively, from anthropogenic climate 
change. The analysis presented provides compelling evidence that Mediterranean biota is far more sensitive to warming than predicted by metabolic theory, as reflected in activation energy typically $>1 \mathrm{eV}$ across processes. We suggest that this reflects the multifaceted role of temperature in affecting biological processes directly, through its metabolic effect, and indirectly through effects on nutrient supply and physical processes and enhancing the vulnerability of biota to other stresses in the ecosystem.

\section{Author Contributions}

Conceived and designed the study: NM, GJ, SA, and CD. Acquired the data: NM, GJ, and CG. Analyzed the data: NM, GJ, and CD. Wrote the paper: NM, GJ, SA, CG, and CD. Final approval of the manuscript: NM, GJ, SA, CG, and CD.

\section{References}

Artale, V., Calmanti, S., Carillo, A., Dell'Aquila, A., Herrmann, M., Pisacane, G., et al. (2010). An atmosphere-ocean regional climate model for the Mediterranean area: assessment of a present climate simulation. Clim. Dyn. 35, 721-740. doi: 10.1007/s00382-009-0691-8

Bensoussan, N., Romano, J. C., Harmelin, J. G., and Garrabou, J. (2010). High resolution characterization of northwest Mediterranean coastal waters thermal regimes: to better understand responses of benthic communities to climate change. Estuar. Coast. Shelf Sci. 87, 431-441. doi: 10.1016/j.ecss.2010.01.008

Berline, L., Siokou-Frangou, I., Marasović, I., Vidjak, O., de Puelles, M. L. F., Mazzocchi, M. G., et al. (2012). Intercomparison of six Mediterranean zooplankton time series. Prog. Oceanogr. 97, 76-91. doi: $10.1016 / j$.pocean.2011.11.011

Bethoux, J. P., and Gentili, B. (1999). Functioning of the Mediterranean Sea: past and present changes related to freshwater input and climate changes. J. Mar. Sys. 20, 33-47. doi: 10.1016/S0924-7963(98)00069-4

Boyce, D. G., Lewis, M. R., and Worm, B. (2010). Global phytoplankton decline over the past century. Nature 466, 591-596. doi: 10.1038/nature09268

Brown, J. H., Gillooly, J. F., Allen, A. P., Savage, V. M., and West, G. B. (2004). Toward a metabolic theory of ecology. Ecology 85, 1771-1789. doi: 10.1890/039000

Burrows, M. T., Schoeman, D. S., Buckley, L. B., Moore, P., Poloczanska, E. S., Brander, K. M., et al. (2011). The pace of shifting climate in marine and terrestrial ecosystems. Science 334, 652-655. doi: 10.1126/science.1210288

Burrows, M. T., Schoeman, D. S., Richardson, A., J., Molinos, J. G., Hoffmann, A., Buckley, L. B., et al. (2014). Geographical limits to species-range shifts are suggested by climate velocity. Nature 507, 492-495. doi: 10.1038/nature12976

Casey, K. S., Brandon, T. B., Cornillon, P., and Evans, R. (2010). "The past, present and future of the AVHRR pathfinder SST program," in Oceanography from Space: Revisited, eds V. Barale, J. F. R. Gower, and L. Alberotanza (Dordrecht; Heidelberg; London; New York: Springer), 273-287.

Dell, A. I., Pawar, S., and Savage, V. M. (2011). Systematic variation in the temperatura dependence of physiological and ecological traits. Proc. Natl. Acad. Sci. 108, 10591-10596. doi: 10.1073/pnas.1015178108

Díaz-Almela, E., Marbà, N., and Duarte, C. M. (2007). Consequences of Mediterranean warming events in seagrass (Posidonia oceanica) flowering records. Glob. Change Biol. 13, 224-235. doi: 10.1111/j.1365-2486.2006.01260.x

Díaz-Almela, E., Marbà, N., Martínez, R., Santiago, R., and Duarte, C. M. (2009). Seasonal dynamics of Posidonia oceanica in Magalluf Bay (Mallorca, Spain): temperature effects on seagrass mortality. Limnol. Oceanogr. 54, 2170-2182. doi: 10.4319/lo.2009.54.6.2170

Diffenbaugh, N. S., Pal, J. S., Giorgi, F., and Gao, X. (2007). Heat stress intensification in the Mediterranean climate change hotspot. Geophys. Res. Lett. 34, L11706. doi: 10.1029/2007GL030000

\section{Acknowledgments}

This research is a contribution to the ESTRESX (CTM201232603) and the CLIMPACT (CGL2014-54246-C2-1-R) projects funded by the Spanish Ministry of Economy and Competitiveness. We thank Xavier Carcelero for assistance during data compilation. GJ also acknowledges a Ramón y Cajal contract (RYC-2013-14714) funded by the Spanish Ministry of Economy and Competitiveness and the Regional Government of the Balearic Islands.

\section{Supplementary Material}

The Supplementary Material for this article can be found online at: http://journal.frontiersin.org/article/10.3389/fmars. 2015.00056

Doney, S. C. (2006). Oceanography: plankton in a warmer world. Nature 444, 695-696. doi: 10.1038/444695a

Duarte, C. M. (2014). Global change and the future ocean: a grand challenge for marine sciences. Front. Mar. Sci. 1:63. doi: 10.3389/fmars.2014.00063

Garrabou, J., Coma, R., Bensoussan, N., Bally, M., Chevaldonne, P., Cigliano, M., et al. (2009). Mass mortality in Northwestern Mediterranean rocky benthic communities: effects of the 2003 heat wave. Glob. Change Biol. 15, 1090-1103. doi: 10.1111/j.1365-2486.2008.01823.x

Giorgi, F., and Lionello, P. (2008). Climate change projections for the Mediterranean region. Glob. Planet. Chang. 63, 90-104. doi: 10.1016/j.gloplacha.2007.09.005

Hedges, L. V., Gurevitch, J., and Curtis, P. S. (1999). The meta-analysis of response ratios in experimental ecology. Ecology 80, 1150-1156. doi: 10.2307/177062

Hoegh-Guldberg, O., Cai, R., Poloczanska, E. S., Brewer, P. G., Sundby, S., Hilmi, K., et al. (2014). “The ocean," in Climate Change 2014: Impacts, Adaptation, and Vulnerability. Part B: Regional Aspects. Contribution of Working Group II to the Fifth Assessment Report of the Intergovernmental Panel on Climate Change, eds V. R. Barros, C. B. Field, D. J. Dokken, M. D. Mastrandrea, K. J. Mach, T. E. Bilir, et al. (Cambridge; New York: Cambridge University Press), 1655-1731

Jordà, G., Marbà, N., and Duarte, C. M. (2012). Mediterranean seagrass vulnerable to regional climate warming. Nature Clim. Change 2, 821-824. doi: $10.1038 /$ nclimate 1533

Kroeker, K. J., Kordas, R. L.,Crim, R., Hendriks, I. E., Ramajo, L., Singh, G. S., et al. (2013). Impacts of ocean acidification on marine organisms: quantifying sensitivities and interaction with warming. Glob. Chang. Biol. 19, 1884-1896. doi: $10.1111 /$ gcb.12179

Lejeusne, C., Chevaldonné, P., Pergent-Martini, C., Boudouresque, C. F., and Pérez, T. (2010). Climate change effects on a miniature ocean: the highly diverse, highly impacted Mediterranean Sea. Tends Ecol. Evol. 25, 250-260. doi: 10.1016/j.tree.2009.10.009

Lyamani, H., Olmo, F. J., Alcántara, A., and Alados-Arboledas, L. (2006). Atmospheric aerosols during the 2003 heat wave in southeastern Spain I: spectral optical depth. Atmos. Environ. 40, 6453-6464. doi: 10.1016/j.atmosenv.2006.04.048

Marbà, N., and Duarte, C. M. (2010). Mediterranean warming triggers seagrass (Posidonia oceanica) shoot mortality. Glob. Chang. Biol. 16, 2366-2375. doi: 10.1111/j.1365-2486.2009.02130.x

Marbà, N., Jordà, G., Agustí, S., Girard, C., and Duarte, C. M. (2015) Impacts of Climate Change on Organisms in the Mediterranean Sea [Dataset]. DIGITAL.CSIC. Available online at: http://hdl.handle.net/10261/116098

Mariotti, A., and Dell'Aquila, A. (2012). Decadal climate variability in the Mediterranean region: roles of large-scale forcings and regional processes. $\mathrm{Clim}$ Dyn. 38, 1129-1145. doi: 10.1007/s00382-011-1056-7

Mazzocchi, M. G., Dubroca, L., García-Comas, C., Di Capua, I., and Ribera d'Alcalà, M. (2012). Stability and resilience in coastal copepod 
assemblages: the case of the Mediterranean long-term ecological research at Station MC (LTER-MC). Prog. Oceanogr. 97-100, 135-151. doi: 10.1016/j. pocean.2011.11.003

Nardelli, B. B., Tronconi, C., Pisano, A., and Santoleri, R. (2013). High and ultra-high resolution processing of satellite sea surface temperature data over Southern European Seas in the framework of MyOcean project. Rem. Sens. Env. 129, 1-16. doi: 10.1016/j.rse.2012.10.012

Nincevic-Gladan, Z., Marasovic, I., Grbec, B., Skejic, S., Buzancic, M., Kuspilic, G., et al. (2010). Inter-decadal variability in phytoplankton community in the Middle Adriatic (Kastela Bay) in relation to the North Atlantic Oscillation. Estuar. Coast. 33, 376-383. doi: 10.1007/s12237-009-9223-3

O'Connor, M. I., Holding, J., Kappel, C. V., Duarte, C. M., Brander, K., Brown, C. J., et al. (2014). Strengthening confidence in climate impacts science. Glob. Ecol. Biogeogr. 24, 64-76. doi: 10.1111/geb.12218

Parmesan, C., Burrows, M. T., Duarte, C. M., Poloczanska, E. S., Richardson, A. J., Schoeman, D. S., et al. (2013). Beyond climate change attribution in conservation and ecological research. Ecol. Let. 16, 58-71. doi: 10.1111/ele. 12098

Poloczanska, E. S., Brown, C. J., Sydeman, W. J., Kiessling, W., Schoeman, D. S., Moore, P. J., et al. (2013). Global imprint of climate change on marine life. Nat. Clim. Change 3, 919-925. doi: 10.1038/nclimate1958

Polovina, J. J., Howell, E. A., and Abecassis, M. (2008). Ocean's least productive waters are expanding. Geophys. Res. Lett. 35, L03618. doi: 10.1029/2007GL031745

Regaudie-de-Gioux, A., and Duarte, C. M. (2013). Global patterns in oceanic planktonic metabolism. Limnol. Oceanogr. 58, 977-986. doi: 10.4319/lo.2013. 58.3.0977
Stott, P. A., Stone, D. A., and Allen, M. R. (2004). Human contribution to the European heatwave of 2003. Nature 432, 610-614. doi: 10.1038/nature03089

Vaquer-Sunyer, R., and Duarte, C. M. (2011). Temperature effects on oxygen thresholds for hypoxia in marine benthic organisms. Glob. Chang. Biol. 17, 1788-1797. doi: 10.1111/j.1365-2486.2010.02343.x

Vaquer-Sunyer, R., Duarte, C. M., Jordá, G., and Ruíz-Halpern, S. (2012). Temperature dependence of oxygen dynamics and community metabolism in a shallow Mediterranean macroalgal meadow (Caulerpa prolifera). Estuar. Coast. 35, 1182-1192. doi: 10.1007/s12237-012-9514-y

Vargas-Yanez, M., García, M. J., Salat, J., García-Martínez, M. C., Pascual, J., and Moya, F. (2008). Warming trends and decadal variability in the Western Mediterranean shelf. Glob. Planet. Chang. 63, 177-184. doi: 10.1016/j.gloplacha.2007.09.001

Conflict of Interest Statement: The Review Editor Dr. Christopher James Brown declares that, despite having collaborated with the author Prof. Carlos M. Duarte, the review process was handled in an impartial manner and no conflict of interest exists. The authors declare that the research was conducted in the absence of any commercial or financial relationships that could be construed as a potential conflict of interest.

Copyright () 2015 Marbà, Jordà, Agustí, Girard and Duarte. This is an open-access article distributed under the terms of the Creative Commons Attribution License (CC $B Y$ ). The use, distribution or reproduction in other forums is permitted, provided the original author(s) or licensor are credited and that the original publication in this journal is cited, in accordance with accepted academic practice. No use, distribution or reproduction is permitted which does not comply with these terms. 